\title{
Spatio-temporal Identification on Cross Border Collaborative Research Trend of Great Lakes by Applied Mathematics Method
}

\author{
Youlin Zhao ${ }^{1, \text { a, } * \text {, Liming Liu }}{ }^{1, \text { b }}$, Li Feng ${ }^{1,2, c}$ \\ ${ }^{1}$ Business School of Hohai University, \#8 Focheng west road, Jiangning District, Nanjing city, \\ Jiangsu Province, PR China \\ ${ }^{2}$ Library of Hohai University, \#1 Xikang Road, Gulou District, Nanjing city, Jiangsu Province, PR \\ China \\ asobzyl@hhu.edu.cn, ${ }^{b} I m-l i u @ h h u . e d u . c n,{ }^{c} f e n g l i \_t s g @ h h u . e d u . c n$, \\ *corresponding author: Youlin Zhao
}

Keywords: Great Lakes, Spatio-temporal Identification, collaborative network, Applied Mathematics Method

Abstract: The main purpose of this paper is to evaluate the global performance and to assess the current spatio-temporal trends on research outputs of Great Lakes in North America by applied mathematics method. The computational science methods were used to survey Great Lakes related articles in the Science Citation Index (SCI) and Social Science Citation Index (SSCI) during the past decades. The Macro level, Meso level and Micro level analysis insights were employed respectively on each dataset. Great Lakes research were mainly completed by USA and Canada institutes, covering $85.87 \%$ among the global research productivities. 7 academic institutes in top 10 productive institutes are located in USA and other 3 institutes are addressed in Canada. 50\% of the top 10 scientists belong to USA, the other $50 \%$ belong to Canada, and every expert published more than 80 papers. In addition, the cognitive learning of citations explained that Great Lakes research domain was focused by USA and Canada community in total citations with an average value on citation per paper. Sweden has the most quantity in citation per paper with a relatively high quality, while in developing countries, its quality of paper needs to be improved such as in P.R China. Institutes with high quality papers are Fisheries \& Ocean Canada, University of Minnesota, NOAA and Wisconsin Department Natural Resources accordingly. Considering the future challenges of climate change and sustainability in freshwater ecosystems, it should be mentioned at this point that the essence of the water security issues should be emphasized on Great Lakes research issues.

\section{Introduction}

Water is a basic need for human survival and necessary condition for social development [26], and also the lifeline of economic development or social progress, even an important material basis for sustainable development $[7,2,22]$. Water, especially fresh water, is one of the most important 
strategic resources, which plays a significant role in the social development and the survival of humankind [34,13].

The main fields of water resource research focus on ecological environment, economy, politics, culture and other fields [33, 29, 6, 16]. In recent years, with the rapid socio-economic development and impact of human activities, people are unbridling to plunder with the nature resources, this results in the emergence of competing for water among people, regional and countries, which taking us pollutants and ecological environment problems, such as water and other undesirable phenomena in ecological environment [18]. With the continuous reduction of water resources, many unexpected things such as increased pollution, weak and loss of normal water function, lost of the balance in hydrological cycle, reduction of water quality et.al. Furthermore, this consequence of actions is recessive, extensive and lagging, it will endanger the natural environment, normal operation of socio-economic system and a virtuous circle when this accumulation reached more than some threshold. Someday, a series of water security issues will be leaded [15, 25, 12, 8, 20, 11, 23].

As the largest surface fresh water system on earth, Great Lakes basin hosts the world's most abundant surface fresh water reserve. Great Lakes is a group of five large interconnected lakes in central North America that consist of lakes Superior, Michigan, Huron, Erie, and Ontario, and constitute the largest area of fresh water in the world. Lake Michigan is wholly within the US, and the others lie on the Canada-US border. Connected to the Atlantic Ocean by the St. Lawrence Seaway, Great Lakes form an important commercial waterway. Great Lakes watershed is home to over 40 million people (Canadian and USA) who depend on a healthy Great Lakes ecosystem for economic, societal and personal vitality. Over 25 million people in the U.S. rely on Great Lakes for their drinking water (U.S. Environmental Protection Agency, 2009). Great Lakes contain about 23,000 km3 (5,500 cu. mi.) of water; cover a total area of 244,000 km2 (94,000 sq. mi.), and account for $90 \%$ of the United States' surface fresh water (20\% of the world's fresh surface water). Great Lakes watershed drains almost 200,000 square miles, has a nearly 10,000-mile-long shoreline, and includes 35,000 islands. Agriculture alone contributes $\$ 53.4$ billion in Canada and the U.S. [14]. Forestry remains a locally important industry throughout much of the watershed. The watershed contains $20 \%$ of all U.S. timberland and $20 \%$ of all U.S. manufacturing (58\% of cars made in the U.S. and Canada are made in the basin). Though Great Lakes are one of America's most important natural features, and they are important to the economy of both U.S. and Canada, environmental issues related to them are often overlooked. However, the healthy functioning of ecosystems in Great Lakes region and the services they provide are important. Unfortunately, the complexity of the interactions between the environmental services provided by the ecosystem and the societal demands upon that ecosystem tend to obscure the importance of tending to the significant impact that over 40 million people are having on this ecosystem [17,5]. Meanwhile, regional climate over Great Lakes Basin will respond to human-induced global warming throughout the 21st century [30].

At present, some new directions and research areas have emerged in Great Lakes research. The history of impairment and management in Great Lakes can be instructive as we consider the future challenges of climate change and sustainability in freshwater ecosystems. Many scientists, stakeholders and government agencies are already involved in research and management of Great Lakes, and one benefit of the multitude of programs is the rich and ever-growing data sets on a variety of physical, chemical, biological and socioeconomic indicators [3]. Water pollution in Great Lakes have attracted increasing attention by water professionals and experts, due to pollution by plastic debris is an increasing environmental concern in Great Lakes where it affects open-water, shoreline, and benthic environments[10]. Great Lakes provides essential ecosystem services to citizens in the basin, such as providing a source of drinking water, a sport fishery, recreational uses of beaches[28], shipping and transportation. This basin is also threatened by stressors common across the globe, such as land use change, pollution from human activities and their interactions 
with climate change [1, 31, 19, 24].

Population growth and development are associated with increased water demand that often exceeds the capacity of existing resources, resulting in water shortages, particularly in urban areas, where more than $60 \%$ of the world's population resides. Energy, food, environment and industrial policies of a nation, all of which have intimate linkages to water. Each will affect the others, and, in turn, be affected by the others. Policies in all these areas will be also influenced by exogenous forces such as demographic transitions, advances in technology and information and communication systems, climatic change, globalization, free trade and increasing social activism [4]. The current and foreseeable development direction of modern society forecasts that future water problem will continue and become increasingly complex as interconnection with economic development fields such as energy, transportation and communication, industry and agriculture, and departments in social or natural systems such as environment, health, education, civilization and culture[9,27,28].

The current and foreseeable development direction of modern society forecasts that future water problem will continue and become increasingly complex as well as interconnection with economic development departments such as energy, transportation and communication, industry and agriculture, and departments in social or natural systems such as environment, health, education, civilization and culture[21]. Therefore, more attentions should be paid to freshwater resource.

Informetrics has been applied for scientific study as the quantitative analysis method and the outcomes of statistics can measure the contribution of scientific publications within a specified theme, as well as describe current research trends that can be used to indicate future study focuses. In this study, the publications of Great Lakes productivity were analyzed carefully.

\section{Data and Method}

This paper is based on the data analysis of the articles from the online Web of Science (WoS) version database which belongs to Thomson Reuters now. The WoS, which from the Institute for Scientific Information (ISI), is the most significant and frequently employed source database reviewing scientific achievements and trends. Therefore, Great Lakes related articles from the WoS were used to investigate the present and future development trends.

The statistical analysis tool is the Thomson Data Analyzer (TDA); the drawing tool is Aureka and MS Office Excel 2010.

\subsection{Data Source}

The data sources came from the WoS Web offered by Clarivate Analystics, and the publishing time span is up to 2016. Data in this paper was acquired on January 28th, 2018 using the topic= (Lake* and (Superior or Michigan or Huron or Erie or Ontario) or "Great lake*") selecting "all the years". Totally 21,836 articles were received from the database of WoS.

\subsection{Analysis Method}

The bibliometric method, which was a branch of intelligence science was firstly proposed by Alan Pritchard in 1969, is widely used to analyze scientific production and research trends in branches of learning. Scientometric analysis is considered as a useful mathematical and statistical method to describe productivity of science, technology and the development trend of research, and can evaluate and predict the relative research with geographic variation in outputs and findings [32]. In this scientometrics study, the paper productivity countries/ institutes/experts, rates of publications, collaborative network and citations from the perspective of Macro level, Meso level and Micro 
level were deeply discussed in the quantitative analysis methods.

\section{Collaborative Analysis}

\subsection{Annual Publications Trend}

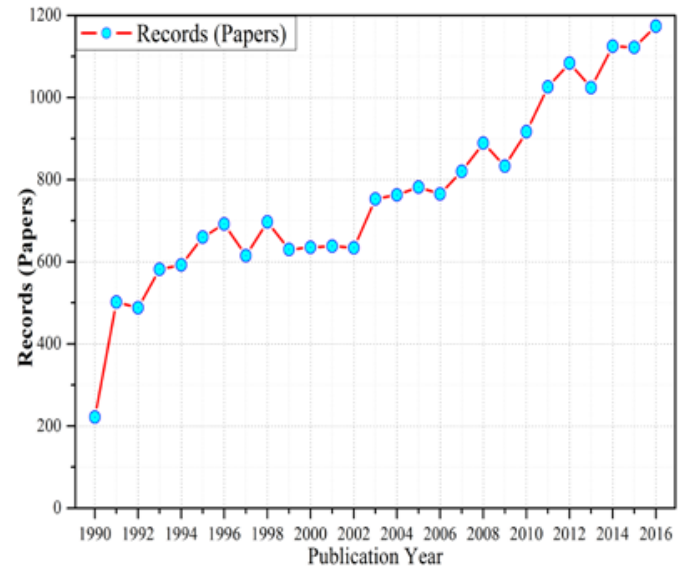

Figure 1 Major related Great Lakes papers records in WoS database.

Figure 1 revealed the publication output of Great Lakes researches from 1990 to 2016. During the past decades, the published paper related to Great Lakes research rose from 200 in 1990 to nearly 1200 in 2016. The annual output of papers increased rapidly between 1990 and 1991 with a reached ratio $60 \%$, and then with a steady growth to 1998 achieved almost 600 . The number of papers almost a horizontal line appeared during 1998 to 2002 and after these years this growth phase is continuing. This feature signifies that Great Lakes is still a popular issue, with higher quality papers will be produced in the future maturity period.

\subsection{Macro Level}

Figures and Tables are used to describe the production and the development trends of Great Lakes research in both the science and social science fields. Publications (as indicator for scientific performance) are commonly accepted indicators for quantitative analysis on innovation research performance.

\subsubsection{Productivity countries on spatial analysis}

From geography spatial distribution in Figure 2, the productivity countries distributed in North America (USA and Canada), Europe (England, Germany, Sweden, France and Spain), Asia (P.R.China and Japan) and Australia. Among them, USA and Canada covered $85.87 \%$ ratio of the whole publications.

\subsubsection{Publications per country per year}

According to the subject categories classification of Thomson Reuters in the Journal Citation Report (JCR), the papers produced during the past two decades per country per year were increased steadily. From the annual publication in Figure 2 from 1997 to 1998 totally increased 100 papers, with a similar trend in Figure 3 for per country in 1997 and 1998. After 1998, it can get a result that the publications in USA described much smoother with no obvious fluctuations. There is an interesting phenomenon that the other countries expect USA, including Canada, owned the same 
growth of fluctuation trend per year. Particular, China showed relatively fastest growing after 2014 compared with the other countries.

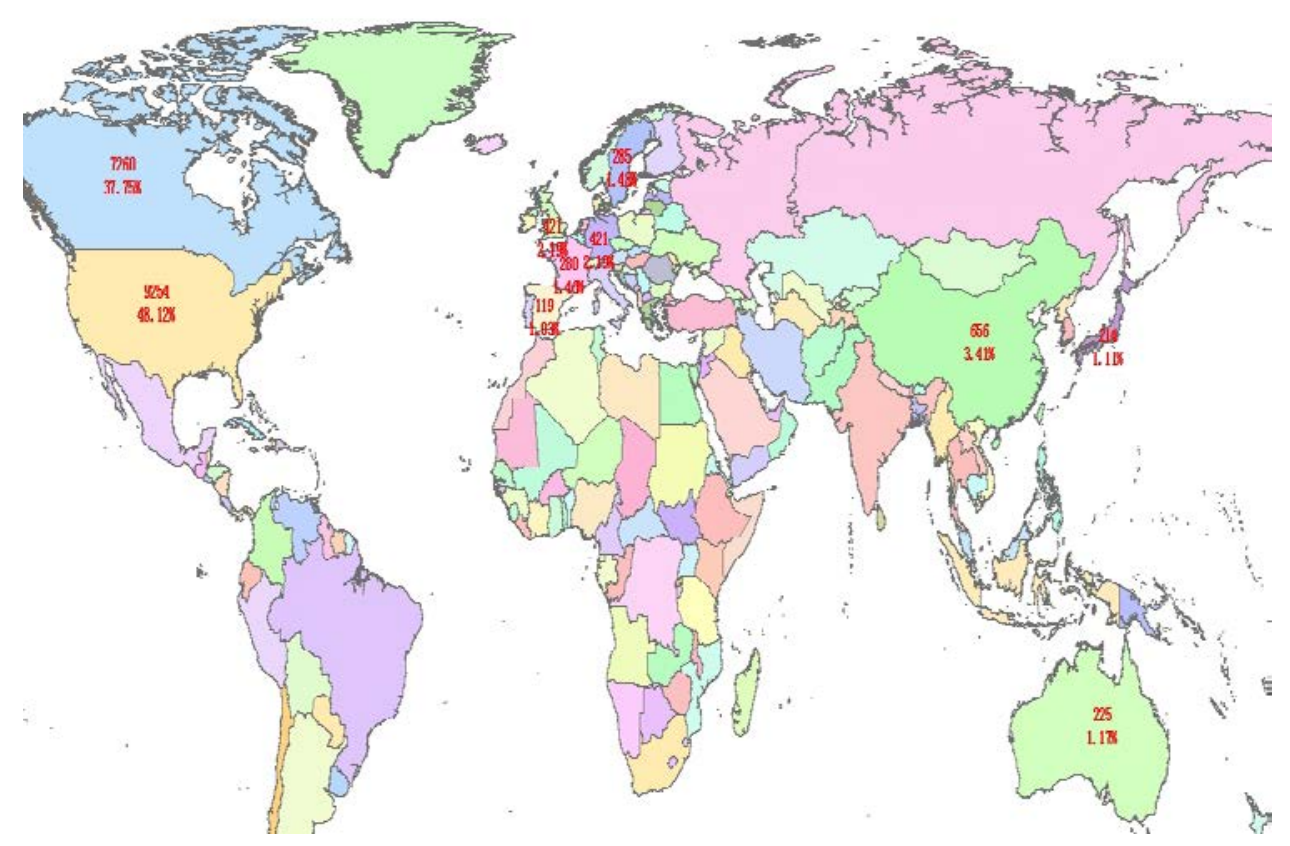

Figure 2 Geographical distribution of the Productivity Countries.

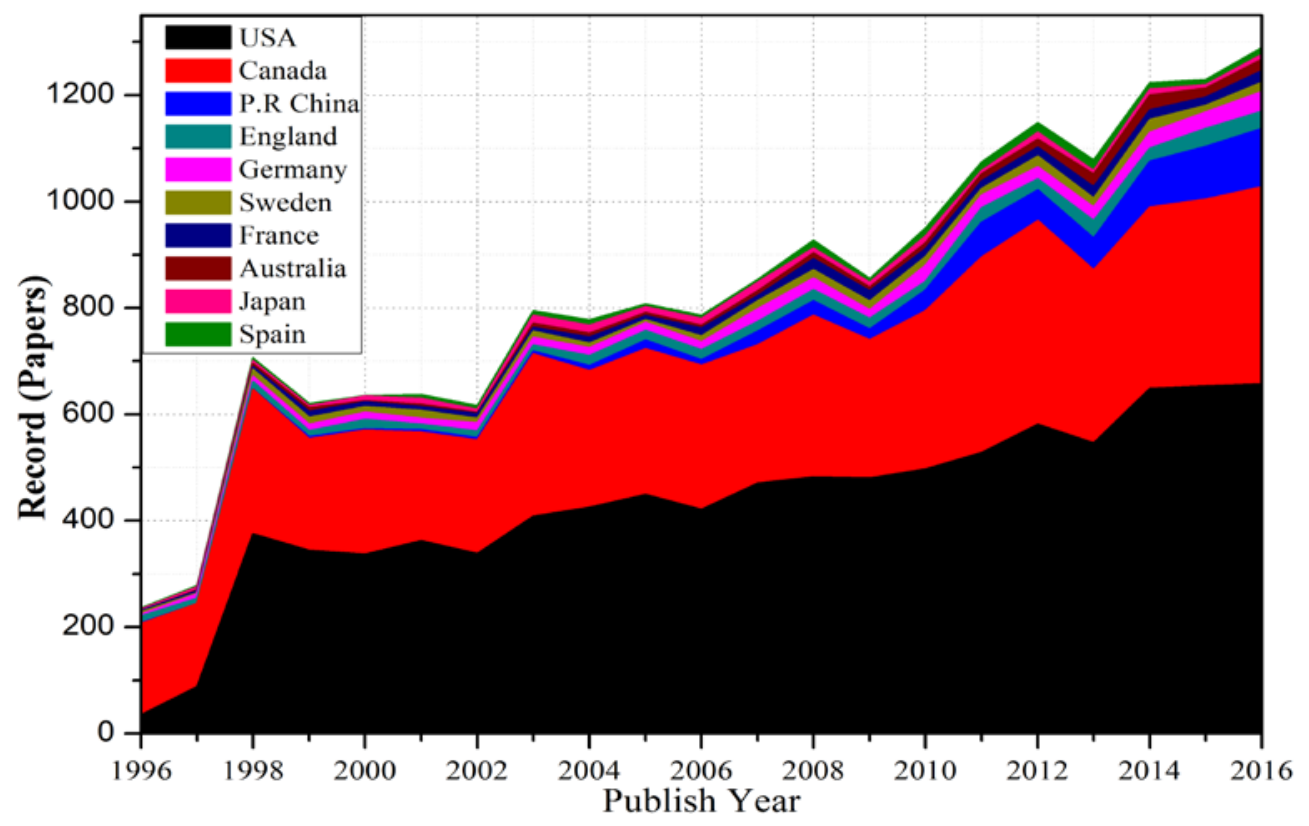

Figure 3 Main country of Great Lakes papers per year in WoS.

\subsubsection{Country Collaborative Network}

From the country collaborative network in Figure 4, USA and Canada are the core central roles with a formal pattern because that the geographical distribution of the two counties around the location of Great Lakes. Obviously, P.R China, Japan, Spain, Italy, France, Sweden, Germany, Switzerland, Netherlands, Scotland, Austria, Norway, England, Belgium and Australia have a relative of the cooperative relationship each other, also with USA and Canada. 


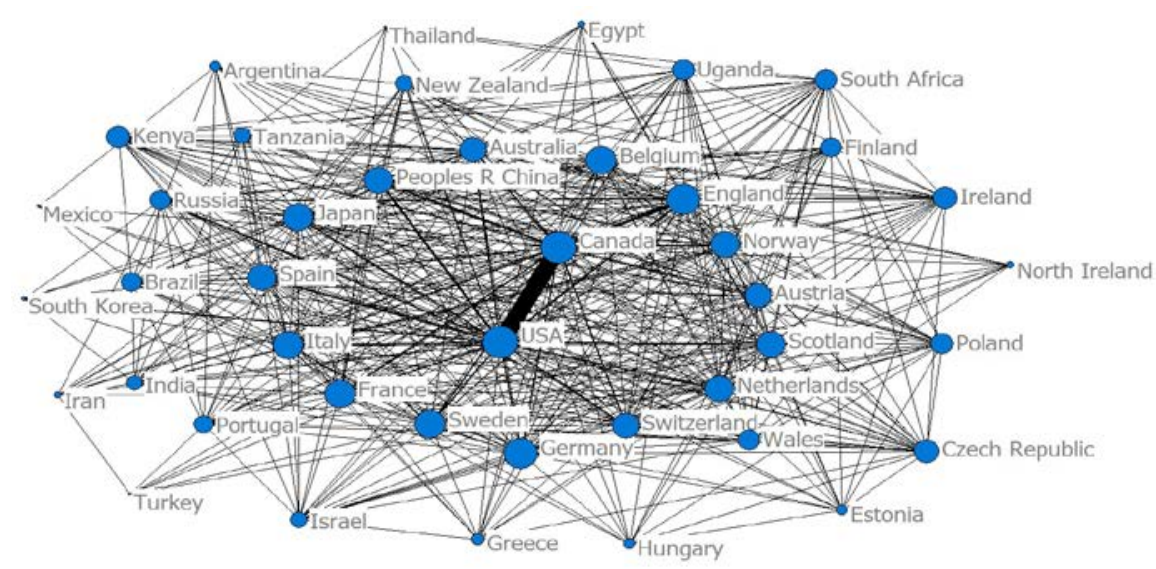

Figure 4 Country collaborative network of Great Lakes papers in WoS.

\subsubsection{Citation per Country}

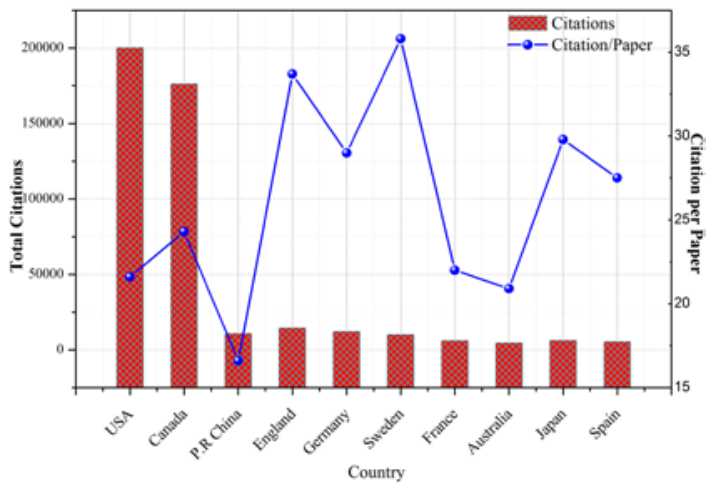

Figure 5 Citation per country of Great Lakes papers in WoS.

From Figure 5, it is seen that USA and Canada have the highest total citations with more than 150,000, as well as the citation per paper with more than 30 in Sweden and England are the highest one. It is interesting that the number of citation/paper among P.R China, England, Germany, Sweden, France, Australia, Japan and Spain shows up and down whilst the difference number of total citations are not great. Especially Sweden has the most quantity number 35 in citation per paper, however, P.R China seems minimal number. It is noteworthy that two largest production countries USA and Canada reached an average value on citation per paper.

\subsection{Meso Level}

\subsubsection{Productivity Institutes}

The top 10 output institutes displayed in Figure 6. It is seen that the University Wisconsin is in the lead position and Environment Canada is in the second, followed by University Michigan, Michigan State University, USA Geological Survey, University Toronto, University Minnesota, National Oceanic and Atmospheric Administration, Wisconsin Department of Natural Resources and Fisheries\& Oceans Canada. This stationary distribution curve may reflect the relationship between productive record and research institute geographical distribution. 7 research institutes in the 10 productive institutes are in USA, the other research institutes are universities in Canada. USA Geological Survey and National Oceanic and Atmospheric Administration in these 7 institutes in USA are scientific agencies of the United States government. From the space distribution of these 
institutes in Figure 7, most of them locate nearby Great Lakes.

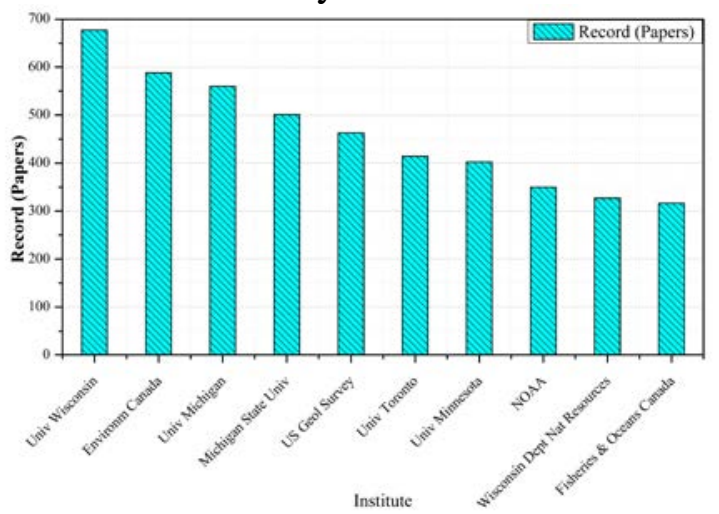

Figure 6 Top productive institute about Great Lakes research.

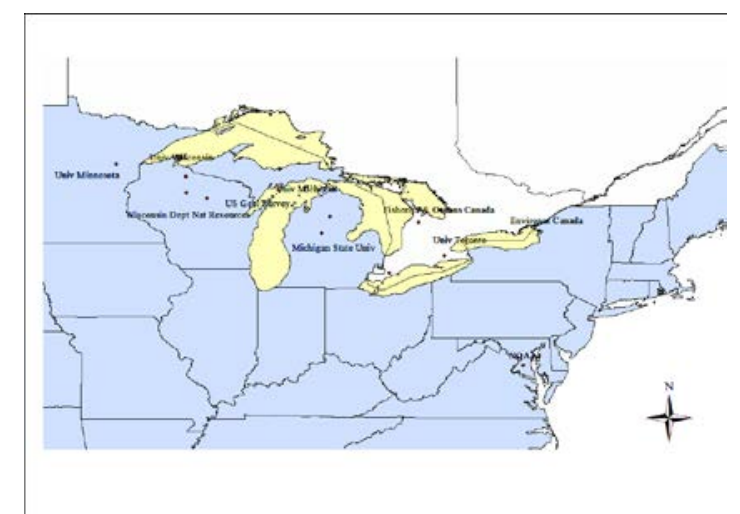

Figure 7 Space distribution of these institutes.

\subsubsection{Publications per institution per year}

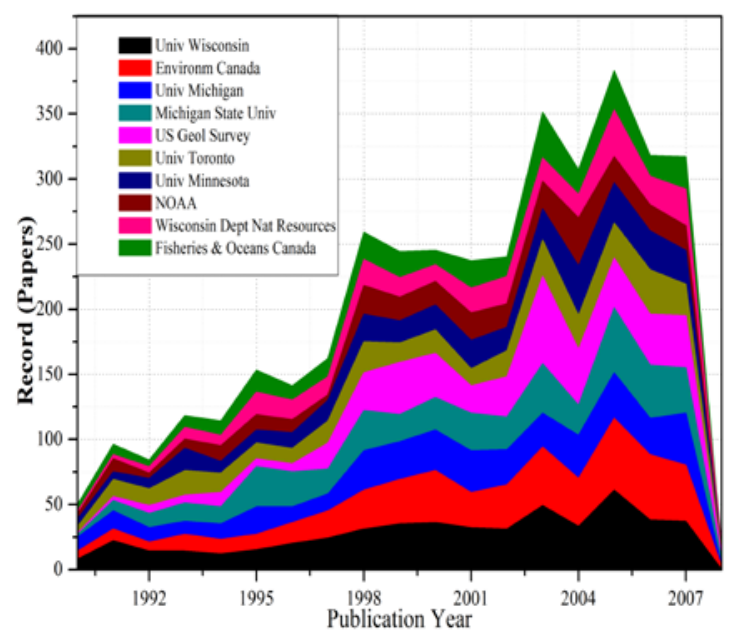

Figure 8 Publications per country per year about Great Lakes.

Figure 8 is a curve of publications per year in top 10 productive institutes during 1990 to 2007. The fluctuation curve shows a similar distribution trend among these institutions. The distribution pattern of publications number is characterized by three peaks pattern (1998, 2003 and 2005) while the most productive year occurring in 2005 with more than 375 publications. 


\subsubsection{Institute Collaborative Network}

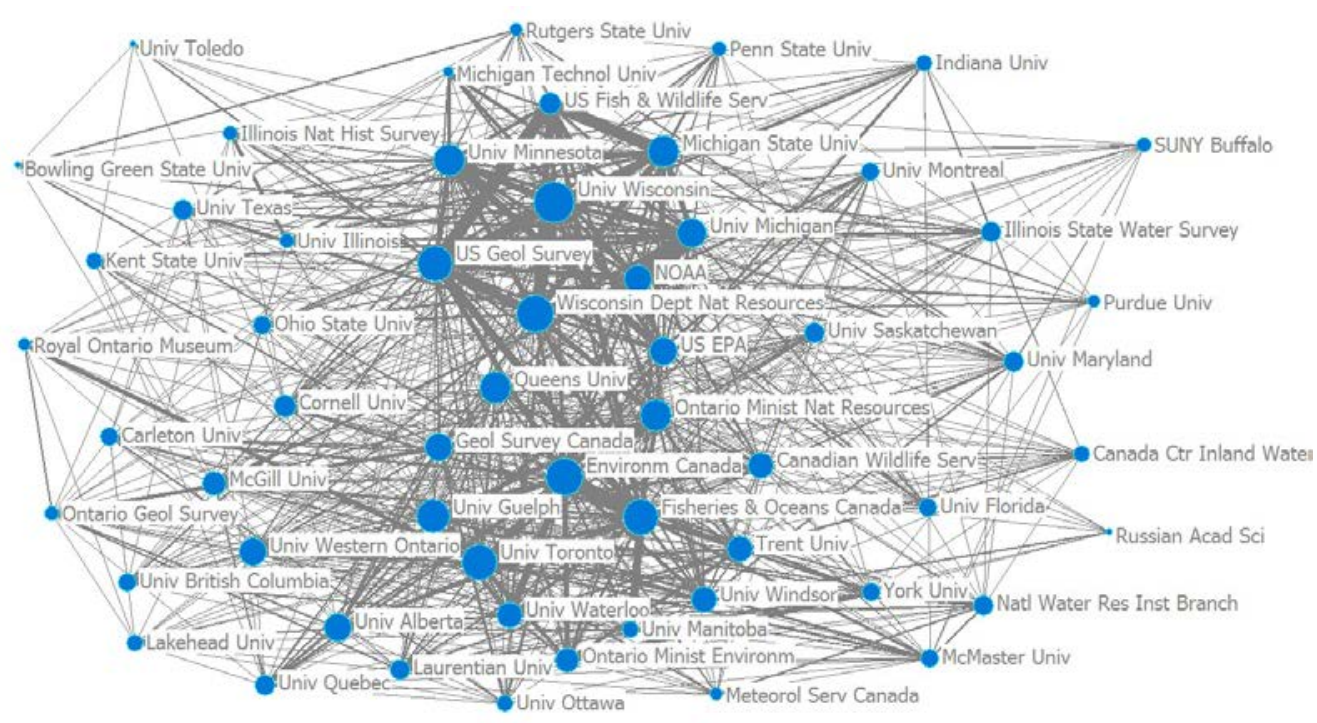

Figure 9 Institute collaborative network of Great Lakes papers in WoS.

Figure 9 is a cooperation of network maps of organizations in Great Lakes research which according to the degree of cooperation between these institutions is clearly seen that some institutions, such as University of Wisconsin, Wisconsin Department of Natural Resources, UAS Geological Survey, Environment Canada, Fisheries \& Oceans Canada, University of Toronto, University pf Guelph, University of Minnesota, University of Michigan, National Oceanic and Atmospheric Administration, United States Environmental Protection Agency and Ministry of Natural Resources and Forestry are in the core status of the network which indicate that these institutions cooperate with other organizations more frequently. It also means these organizations play an import part in the process of knowledge transfer in Great Lakes on a global scale. Some institutions lower in paper production such as University of Toledo, Bowling Green State University and Russian Academy of Sciences scatter fringer of the network because of less cooperation. In addition, there is a big cooperation circle in the middle of this map. It can be concluded that these significant institutions mostly belong to USA and Canada. Therefore it can be safely concluded that USA and Canada have huge advantages and development strength prospects in these fields.

\subsubsection{Citation per Institute}

Total citing and average citation frequencies in the field of Great Lakes research of top 10 institutions are shown in Figure 10. The Fisheries \& Oceans Canada has the highest in citation per paper followed by University of Minnesota, Environment of Canada and University of Michigan. Total citations list in descending order are University of Wisconsin, Environment Canada, University of Michigan, Michigan State University and University of Minnesota. The total citation of the University of Toronto is the same as citation per paper, and the citation per paper of Fisheries \& Oceans Canada is far more than the second one and other institutions. Moreover, Fisheries \& Ocean Canada, University of Minnesota, NOAA and Wisconsin Department Natural Resources are more than the total citations indicating paper quality of these institutions are higher. 


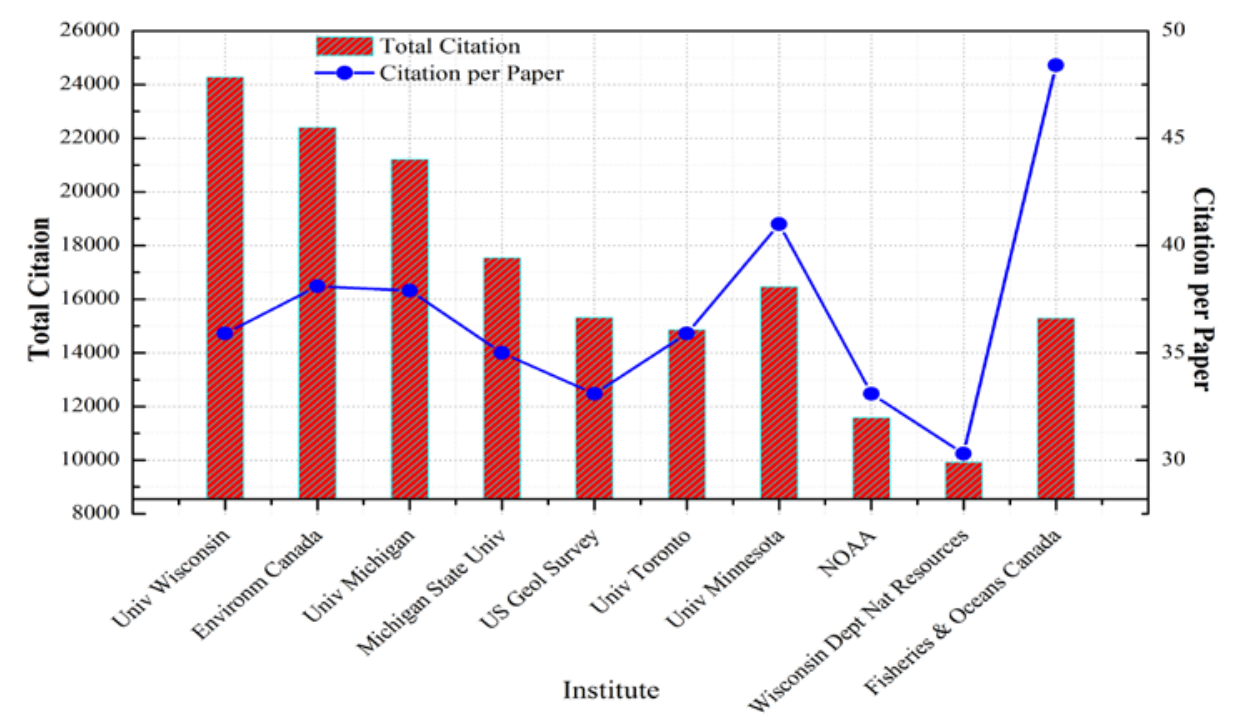

Figure 10 Citation of top productive institution on Great Lakes publications.

\subsection{Micro Level}

\subsubsection{Productivity Experts}

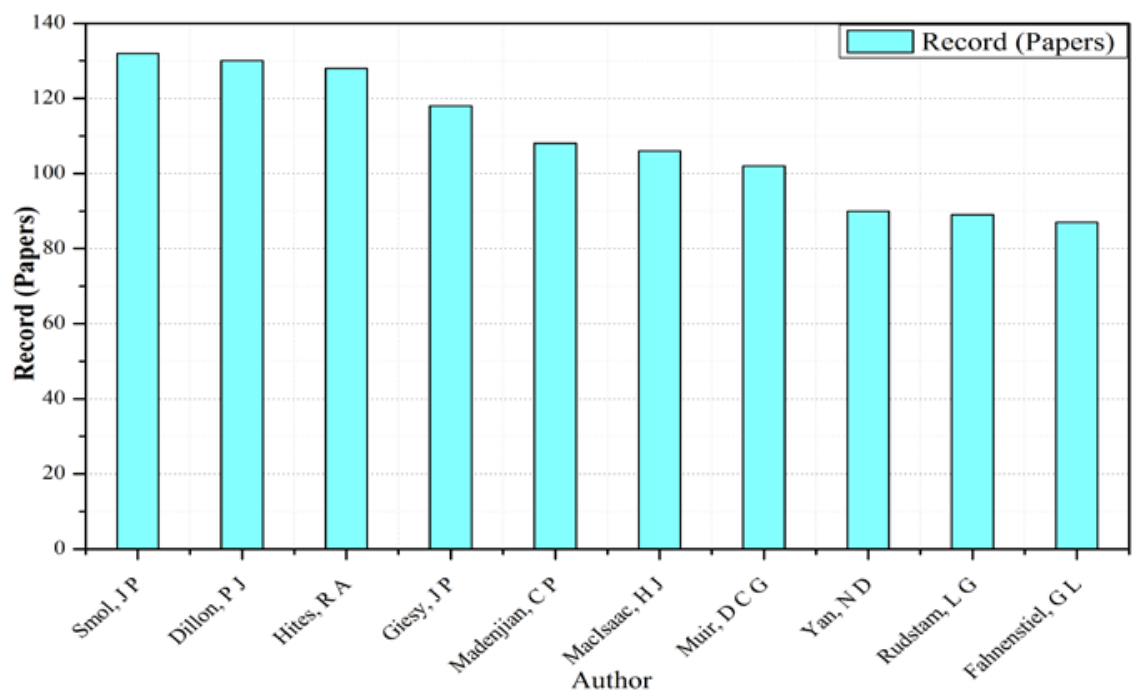

Figure 11 Top author of Great Lakes papers published in WOS.

Figure 11 identifies the 10 authors with a paper productivity of 80 or more. Smol JP, Dillon PJ and Hites RA performed well and exceeded other authors in total number of paper with more than 120, followed by Giesy JP, Madenjian CP and MacIsaac HJ. These top 10 authors 50\% belong to USA, the other $50 \%$ belong to Canada.

\subsubsection{Publications per country per year}

The top 10 output authors are displayed in Figure 12. Their historic performance in the past decade is also described. The output of these authors almost started a fluctuating trend rising, especially Dillon PJ published a highest number with 16 in 2003, following by Smol JP with 13 in 2012 and Madenjian CP with 13 in 2014. While every year with the exception of 2008 showed a declined popularity with these 10 authors, probably affected by the global financial crisis. 


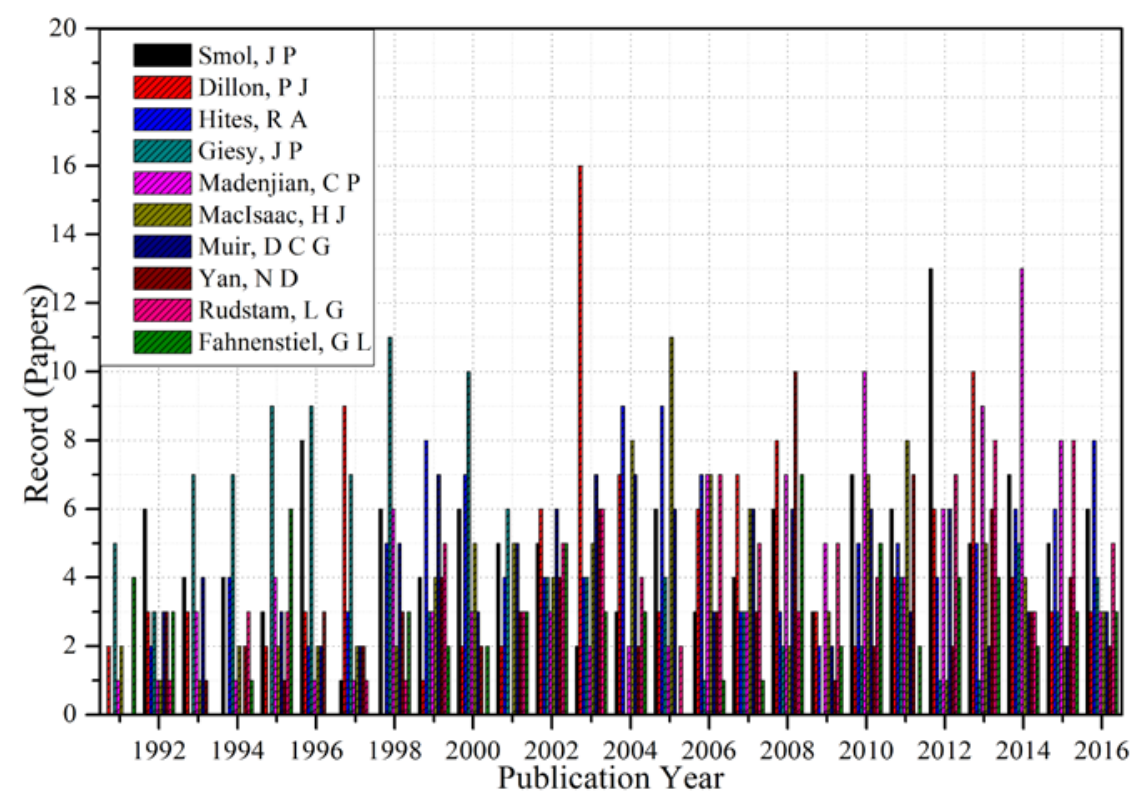

Figure 12 Top authors publications per year about Great Lakes.

\subsubsection{Experts Collaborative Network}

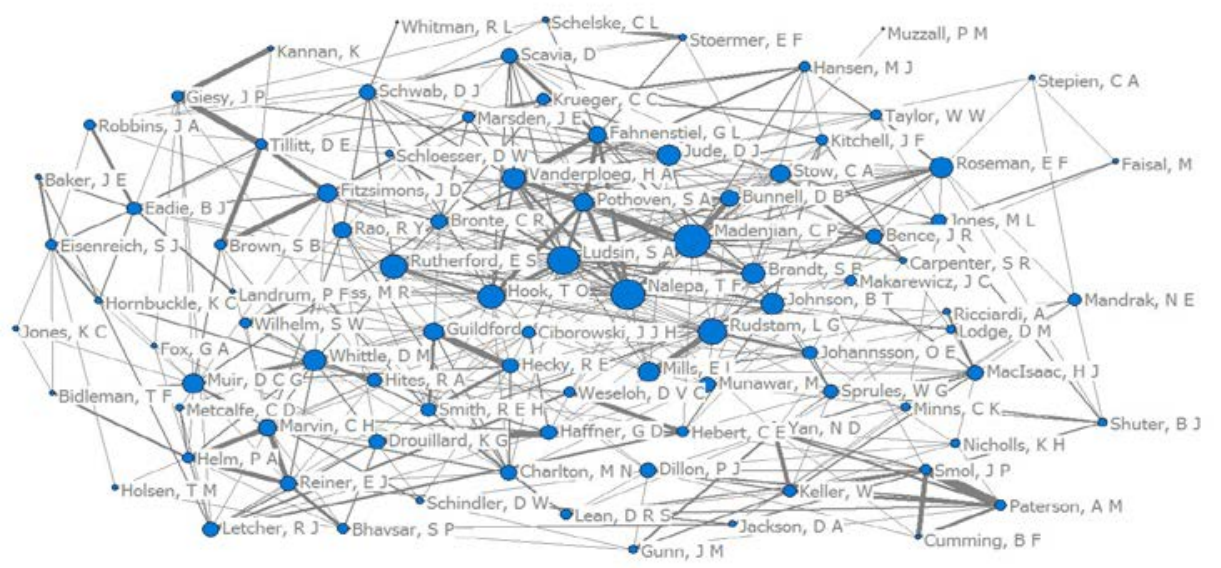

Figure 13 The collaboration map of authors with Great Lakes papers.

Figure 13 is a cooperative network map and national cooperative relationship of Great Lakes has been displayed in accordance with the author cooperation degree. The thickness of the lines between authors can reflect their degree of cooperation. Madenjian. CP, Nalepa. TF, Ludsin, SA Vanderploeg, HA and Fahnenstiel, GL cooperate frequently with each other and the Madenjian, CP and Nalepa, TF have the core position in the network. This network can describe that both of these authors benefits from the knowledge transfer among Great Lakes research. Other authors such as Rutherford, ES and Hook, TO, Rudstam, LG and Mills, EI are in the peripheral layer of the cooperation network and have some cooperation with each other.

\subsubsection{Citation per Author}

Total citing and average citation frequencies in the field of Great Lakes research from top 10 authors are shown in Figure 14. Hites RA was the highest author in total citing count followed by Giesy JP, Dillon PJ, MacIsaas HJ and Muir DCG. The citations per paper listed in descending order 
are Hites RA, Giesy JP, MacIsaas HJ, Muir DCG and Dillon PJ. Hites RA is first, and Giesy JP is second in total citing and average citation frequencies. This condition indicates the high quality of the papers published by these authors. Ten authors excluding Hites RA, Dillon PJ and Smol JP were more than the total citations indicating paper quality of these authors are higher.

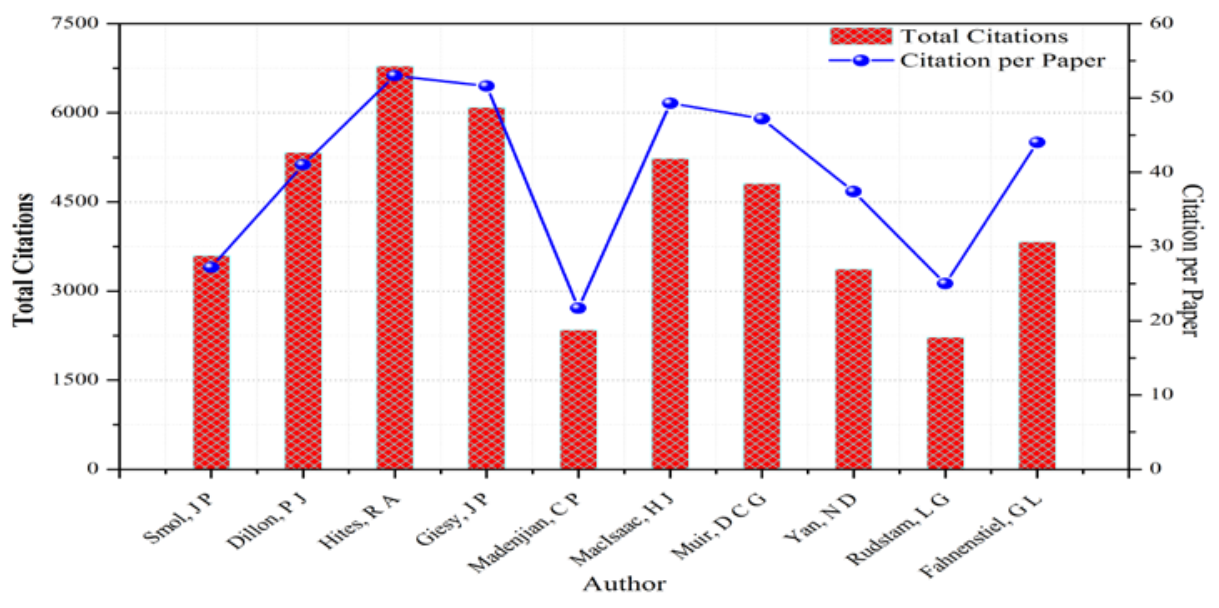

Figure 14 Citation distribution of WoS Great Lakes papers.

\section{Conclusion}

The future challenges of climate change and sustainability in freshwater ecosystems of Great Lakes is becoming more serious. Great Lakes provides essential ecosystem services to citizens in the basin, such as providing a source of drinking water, a sport fishery, recreational uses of beaches, shipping and transportation. This basin is also threatened by stressors common across the globe, such as land use change, pollution from human activities and their interactions with climate change. This study showed some remarkable viewpoints on the world-wide Great Lakes research trends and performance from.

Great Lakes research showed an upward trend as the SCI and SSCI paper production increased steadily in the last three decades and rapidly in the last 10 years. Great Lakes research mainly focused by USA and Canada, covered $85.87 \%$ ratio among the productivity countries. 7 research institutes in top 10 productive institutes are in USA and other 3 institutes are in Canada. From the space distribution of these institutes, most of the top 10 productive institutes locate nearby Great Lakes. $50 \%$ of the top 10 authors belong to USA, the other $50 \%$ belong to Canada, and every expert published 80 or more papers.

In addition, the analysis of citation explained that Great Lakes research was domain focused by USA and Canada in total citations with an average value on citation per paper. Especially Sweden has the most quantity in citation per paper with a relatively high quality, whilst in developing countries such as P.R China, its quality of paper needs to be improved. Paper quality of institutions is high including Fisheries \& Ocean Canada, University of Minnesota, NOAA and Wisconsin Department Natural Resources.

Figures and tables in this paper describe the entire performance, distribution and the trend of Great Lakes research. The explain result will be conducive to researchers who study this field. Nevertheless, papers about Great Lakes are so numerous scattering in a number of databases that some high-quality papers may not be analyzed. Great Lakes basin is the largest surface fresh water system on earth, providing essential ecosystem services to citizens such as a source of drinking water, a sport fishery, and recreational uses of beaches, shipping and transportation. This basin is also threatened by stressor common across the globe, such as land use change, pollution from 
human activities and their interactions with climate change. Considering the future challenges of climate change and sustainability in freshwater ecosystems, it should be mentioned at this point that the essence of the water security issues is Great Lakes issues. Great Lakes research should be given more priority.

\section{Acknowledgments}

This work was supported by the National Natural Science Foundation of China, No. 71503068 and 71603075; National Philosophy and Social Science Fund Key Grant, No.16AGL005 and No. 11\&ZD168.

\section{References}

[1] Allan JD, McIntyre PB, Smith SDP, Halpern BS, Boyer GL, Buchsbaum A, Burton GA, Campbell LM, Chadderton WL, Ciborowski JJH, Doran PJ, Eder T, Infante DM, Johnson LB, Joseph CA, Marino AL, Prusevich A, Read JG, Rose $J B$, Rutherford ES, Sowa SP, Steinman AD. (2013) Joint analysis of stressors and ecosystem services to enhance restoration effectiveness. Proceedings of the National Academy of Sciences, 110(1), 372-377.

[2] Arico C, Lo Re C. (2016) A non-hydrostatic pressure distribution solver for the nonlinear shallow water equations over irregular topo vgraphy. ADV WATER RESOUR, 98, 47-69.

[3] Baustian MM, Mavrommati G, Dreelin EA, Esselman P, Schultze SR, Qian L, Aw TG, Luo L, Rose JB. (2014) A one hundred year review of the socioeconomic and ecological systems of Lake St. Clair, North America. J GREAT LAKES RES, 40(1), 15-26.

[4] Biswas AK, Seetharam KE. (2008) Achieving water security for Asia. INT J WATER RESOUR D, 24(1), 145-176.

[5] Breffle WS, Muralidharan D, Donovan RP, Liu F, Mukherjee A, Jin Y. (2013) Socioeconomic evaluation of the impact of natural resource stressors on human-use services in the Great Lakes environment: A Lake Michigan case study. RESOURCES POLICY, 38(2), 152-161.

[6] Brown C, Werick W, Leger W, Fay D. (2011) A Decision-Analytic Approach to Managing Climate Risks: Application to the Upper Great Lakes. J AM WATER RESOUR AS, 47(3), 524-534.

[7] Cirpka OA, Valocchi AJ. (2016) Debates-Stochastic subsurface hydrology from theory to practice: Does stochastic subsurface hydrology help solving practical problems of contaminant hydrogeology? WATER RESOUR RES, 52(12), 9218-9227.

[8] Cirpka OA, Valocchi AJ. (2016) Debates-Stochastic subsurface hydrology from theory to practice: Does stochastic subsurface hydrology help solving practical problems of contaminant hydrogeology? WATER RESOUR RES, 52(12), 9218-9227.

[9] Constantine K, Massoud M, Alameddine I, El-Fadel M. (2017) The role of the water tankers market in water stressed semi-arid urban areas:Implications on water quality and economic burden. J ENVIRON MANAGE, 188, 85-94.

[10] Driedger AGJ, Duerr HH, Mitchell K, Van Cappellen P. (2015) Plastic debris in the Laurentian Great Lakes: A review. J GREAT LAKES RES, 41(1), 9-19.

[11] Fiori A, Cvetkovic V, Dagan G, Attinger S, Bellin A, Dietrich P, Zech A, Teutsch G. (2016) Debates-Stochastic subsurface hydrology from theory to practice: The relevance of stochastic subsurface hydrology to practical problems of contaminant transport and remediation. What is characterization and stochastic theory good for? WATER RESOUR RES, 52(12), 9228-9234.

[12] Fogg GE, Zhang Y. (2016) Debates-Stochastic subsurface hydrology from theory to practice: A geologic perspective. WATER RESOUR RES, 52(12), 9235-9245.

[13] Frolund B, Palmgren R, Keiding K, Nielsen PH. (1996) Extraction of extracellular polymers from activated sludge using a cation exchange resin. WATER RES, 30(8), 1749-1758.

[14] Furness R. (2008) A valuation of ecological services in the laurentian great lakes basin with an emphasis on Canada, 100,pg 54, 2008). J AM WATER WORKS ASS, 100(8), 131

[15] Li Q, Mahendra S, Lyon DY, Brunet L, Liga MV, Li D, Alvarez PJJ. (2008) Antimicrobial nanomaterials for water disinfection and microbial control: Potential applications and implications. WATER RES, 42(18), 4591-4602.

[16] Lin Y, Wu CH. (2014) A field study of nearshore environmental changes in response to newly-built coastal structures in Lake Michigan. J GREAT LAKES RES, 40(1), 102-114.

[17] Mayer A, Mubako S, Ruddell BL. (2016) Developing the greatest Blue Economy: Water productivity, fresh water depletion, and virtual water trade in the Great Lakes basin. EARTHS FUTURE, 4(6), 282-297.

[18] Muniruzzaman M, Rolle M. (2016) Modeling multicomponent ionic transport in groundwater with IPhreeqc 
coupling: Electrostatic interactions and geochemical reactions in homogeneous and heterogeneous domains. ADV WATER RESOUR, 98, 1-15.

[19] Pirrone N, Keeler GJ. (1996) A preliminary assessment of the urban pollution in the Great Lakes region. SCI TOTAL ENVIRON, 189, 91-98.

[20] Rajaram H. (2016) Debates-Stochastic subsurface hydrology from theory to practice: Introduction. WATER RESOUR RES, 52(12), 9215-9217.

[21] Ren J, Lyu P, Wu X, Ma F, Wang Z, Yang G. (2013) An Informetric Profile of Water Resources Management Literatures. WATER RESOUR MANAG, 27(13), 4679-4696.

[22] Sanchez-Vila X, Fernandez-Garcia D. (2016) Debates-Stochastic subsurface hydrology from theory to practice: Why stochastic modeling has not yet permeated into practitioners? WATER RESOUR RES, 52(12), 9246-9258.

[23] Sanchez-Vila X, Fernandez-Garcia D. (2016) Debates-Stochastic subsurface hydrology from theory to practice: Why stochastic modeling has not yet permeated into practitioners? WATER RESOUR RES, 52(12), 9246-9258.

[24] Sierszen ME, Morrice JA, Trebitz AS, Hoffman JC. (2012) A review of selected ecosystem services provided by coastal wetlands of the Laurentian Great Lakes. AQUAT ECOSYST HEALTH, 15(1), 92-106.

[25] Su C. (2017) Environmental implications and applications of engineered nanoscale magnetite and its hybrid nanocomposites: A review of recent literature. J HAZARD MATER, 322(SIA), 48-84.

[26] Ternes TA. (1998) Occurrence of drugs in German sewage treatment plants and rivers. WATER RES, 32(11), 3245-3260.

[27] Voeroesmarty CJ, McIntyre PB, Gessner MO, Dudgeon D, Prusevich A, Green P, Glidden S, Bunn SE, Sullivan CA, Liermann CR, Davies PM. (2010) Global threats to human water security and river biodiversity. NATURE, 467(7315), 555-561.

[28] Voeroesmarty CJ, McIntyre PB, Gessner MO, Dudgeon D, Prusevich A, Green P, Glidden S, Bunn SE, Sullivan CA, Liermann CR, Davies PM. (2010) Global threats to human water security and river biodiversity (vol 467, pg 555, 2010). NATURE, 468(7321), 334.

[29] Wandera L, Mallick K, Kiely G, Roupsard O, Peichl M, Magliulo V. (2017) Upscaling instantaneous to daily evapotranspiration using modelled daily shortwave radiation for remote sensing applications: an artificial neural network approach. HYDROL EARTH SYST SC, 21(1), 197-215.

[30] Wang X, Huang G, Baetz BW, Zhao S. (2017) Probabilistic projections of regional climatic changes over the Great Lakes Basin. CLIM DYNAM, 49(7-8), 2237-2247.

[31] Welsh AB, Scribner K, Stott W, Walsh MG. (2017) A population on the rise: The origin of deepwater sculpin in Lake Ontario. J GREAT LAKES RES, 43(5), 863-870.

[32] Yao Q, Chen J, Lyu P, Zhang S, Ma F, Fang J. (2012) Knowledge map of artemisinin research in SCI and Medline database. J VECTOR DIS, 49(4), 205-216.

[33] Yin J, He F, Xiong YJ, Qiu GY. (2017). Effects of land use/land cover and climate changes on surface runoff in a semi-humid and semi-arid transition zone in northwest China. HYDROL EARTH SYST SC, 21(1), $183-196$.

[34] Zhu L, Yu H, Liu Y, Qi H, Xu X. (2015). Optimization for extracellular polymeric substances extraction of microbial aggregates. WATER SCI TECHNOL, 71(7), 1106-1112. 